\title{
1 Encapsulation of phase change materials using rice-husk-char
}

2 Wayne Gondora ${ }^{1}$, Khalid Doudin ${ }^{1}$, Daniel J. Nowakowski ${ }^{2}$, Bo Xiao ${ }^{3}$, Yulong Ding ${ }^{4}$, Tony

${ }^{1}$ Aston Material Centre, Aston University, Birmingham, B4 7ET, UK;

$5 \quad{ }^{2}$ European Bioenergy Research Institute, School of Engineering and Applied Sciences, Aston $6 \quad$ University, Birmingham, B4 7ET, UK;

$7{ }^{3}$ School of Chemistry and Chemical Engineering, Queen's University Belfast, Belfast BT9 5AG, $8 \quad \mathrm{UK}$;

$9{ }^{4}$ Birmingham Centre for Energy Storage, School of Chemical Engineering, University of Birmingham, Edgbaston, Birmingham, B15 2TT, UK.

*Corresponding author: q.yuan@aston.ac.uk

\section{ABSTRACT}

This paper explored a new approach to prepare phase change microcapsules using carbon-based particles via Pickering emulsions for energy storage applications. A rice-husk-char, a by-product in biofuel production, containing $53.58 \mathrm{wt} \%$ of Carbon was used as a model carbon-based material to encapsulate hexadecane, a model phase change material. Hexadecane was emulsified in aqueous suspensions of rice-husk-char nanoparticles. Water soluble polymers poly(diallyldimethylammonium chloride) and poly(sodium styrene sulfonate) were used to fix the rice-husk-char nanoparticles on the emulsion droplets through layer-by-layer assembly to enhance the structural stability of the microcapsules. The microcapsules formed are composed of a thin shell encompassing a large core consisting of hexadecane. Thermal gravimetrical and differential scanning calorimeter analyses showed the phase change enthalpy of $80.9 \mathrm{~kJ} \mathrm{~kg}^{-1}$ or $120.0 \mathrm{MJ} \mathrm{m}^{-3}$. Design criteria of phase change microcapsules and preparation considerations were discussed in terms of desired applications. This work demonstrated possible utilisations of biomass-originated carbon-based material for thermal energy recovery and storage applications, which can be a new route of carbon capture and utilisation.

Keywords: Thermal energy storage, phase change microcapsules, rice husk char, Pickering emulsion, layer-by-layer assembly

\section{INTRODUCTION}

Energy consumed for low and intermediate rank heat accounts for $\sim 90 \%$ of energy consumption in industrial and household applications [1]. A large proportion of the heat is discharged into the 
environment through undesired heat loss in maintaining temperatures. In order to reduce the overall energy consumption and $\mathrm{CO}_{2}$ emission worldwide, cost-effective thermal systems have been under development to reduce the heat loss and to harvest solar energy and store it as heat for reuse [2, 3]. Thermal media is a key to effective thermal systems. In general, the desired thermal media should have (a) a high dynamic thermal energy density; (b) long term stability and (c) low cost for economic sustainability and (d) excellent flow and heat transportation properties (if in the form of working fluids). Phase change material slurries have been developed to serve as thermal fluids for both heat transfer and energy storage [2,3], where the phase change materials encapsulated are dispersed in an immiscible liquid carrier in order to maintain the fluidity of the media during phase changes. In this way, the phase change material slurries have higher heat density at points around the phase change temperature and also the desired fluidity.

Active research into phase change microcapsules by experiments and simulations in different thermal systems are reviewed in references [3, 4]. Different results were observed in relation to application scenarios. The well-known Micronal ${ }^{\circledR}$ phase change microcapsules were commercialised, which can be incorporated in interior walls of buildings for intelligent temperature management. Its enhancement in energy efficiency has been well approved in the stagnant environment for a low frequency heat charge and discharge $[5,6]$, but its economic efficiency has been questioned. In laminar or transient flow regions, heat transfer enhancements can be spotted clearly in heat pumps [7]. While enhancements are less significant in more intense processing environments such as solar heat harvest and release due to slow heat transfer rates [8, 9].

Critical analysis has shown that polymers such as poly(methyl methacrylate) such as poly(methyl methacrylate) [10, 11], poly(melamiformaldehyde) [4, 12], poly urea and (urea formaldehyde) [4, 12], polystyrene [13] and polyethylene [14] are common encapsulates studied for phase change microcapsules. These polymers inherently have low thermal conductivities $\left(\sim 0.25 \mathrm{~W} \mathrm{~m}^{-1} \mathrm{~K}^{-1}\right)$ and low densities, hence slow heat capture and release rates and limited volumetric heat densities. In recent years, inorganic materials including metal, metal oxides, insoluble salts and carbon-based materials (graphene and carbon nanotube) have been used in the modification of the microcapsule shell by coating or as additives for enhancing their thermal conductivity. Microcapsules with silver coating as the second layer $[15,16]$, hybrid magnetic $\mathrm{Fe}_{3} \mathrm{O}_{4} / \mathrm{SiO}_{2}$ [17], silicon nitride powdermodified polymethylmethacrylate [18] and calcium carbonate shells [19] have all displayed significant improvements in thermal conductivity. 
Carbon-based materials varying from diamond, graphite (carbon fibre), carbon nanotubes and graphene to amorphous carbons are well known for their wide range of thermal conductivities $(\sim 21$ - $5000 \mathrm{~W} \mathrm{~m}^{-1} \cdot \mathrm{K}^{-1}$ ). The addition of $20 \mathrm{wt} \%$ expanded graphite in paraffin results in a 7.5 fold thermal conductivity increase for the formation of a carbon network structure [20]. As an example composite panels consisting of phase change materials and expanded graphite (ECOPHIT®) installed as radiant ceilings at the Deutsche Bank headquarters demonstrated a $67 \%$ reduction in energy use for heating and cooling $[21,22]$. Both the heat storage capacity of the phase change materials and the high thermal conductivity of graphite sheets contributed to the result. Phase change microcapsules of urea-formaldehyde resin with $4 \%$ of carbon nanotubes showed an increase in thermal conductivity by $79.2 \%$ compared with that without carbon nanotubes [23]. These results inspire researchers to develop carbon-based phase change microcapsules aiming at achieving large heat capacities and high heat transfer rates as desired properties.

Using carbon-based materials as microcapsule shells their absolute thermal conductivity is expected to be higher than that of polymer nanocomposites containing a small fraction of carbon nanotubes [23-25]. However, high thermal conductive carbon materials can form only at high temperatures, typically above $600^{\circ} \mathrm{C}$, which is much higher than the decomposition temperature of organic carbon-carbon bonds. As a result, it is very difficult to grow thermally conductive carbon on the surface of phase change "droplets". Fortunately, solid particles can be directly used to manufacture microcapsules through a Pickering emulsion, which is the emulsion using solid particles as emulsifier [26]. All the carbon materials mentioned above are available as solid microor nanoparticles.

Pickering emulsion droplets are formed by the adsorption of one monolayer of solid particles on the droplet surface, thus generating core-shell structures [27, 28]. Many different types of inorganic nanoparticles such as silica [26-28], metal organic framework nanoparticles [29, 30] and carbon nanotubes [31] have been successfully incorporated in stabilising Pickering emulsions either as a single emulsifier or co-emulsifier [32], among which silica nanoparticles have been more extensively studied. For example, Ding et. al. prepared structured microcapsules using silica nanoparticles that are formed in-situ by the hydrolysis of methyl trimethoxysilane and 3aminopropyl trimethoxysilane [28]. The prepared microcapsules contained a significant core of $n$ octodecane, a phase change material, with a monolayer of silica nanoparticles as shell giving a high volumetric encapsulation ratio of $65 \mathrm{wt} \%$. The nanoparticles can be manipulated for the desired arrangement on the droplet surface through tailoring size, shape, surface chemistry and adsorption kinetics [32]. Pickering emulsions, in particular those stabilised by latex nanoparticles, 
have been successfully encapsulated by polymer melting $[33,34]$, cross-linking from the inside [27] or outside of microcapsules. The microcapsule wall formed has been tailored to have a different permeability from vapour-proof to highly porous with desired pore sizes [27, 28, 34]. This knowledge stimulated our study of using carbon-based particles to produce phase change microcapsules.

The model carbon-based material used in this study is rice-husk-char, which is rich in carbon and silica $[35,36]$. It is an abundant by-product in countries which produce and consume rice. Up to now, there are insufficient applications of rice-husk-char to support a sustainable consumption chain. This study proposes its use in the development of new applications of carbon-based materials for thermal energy storage in civil engineering.

Rice husk char used in this study was obtained from slow pyrolysis for bio-oil production. After milling down to desired sizes the rice husk char particles were dispersed in water to be used as a solid emulsifier in the stabilisation of phase change material emulsion. The emulsion droplets were then subjected to a layer by layer assembly of polyelectrolyte chains in an aqueous solution for encapsulation. Following this, thermogravimetric and differential scanning calorimetric analyses were carried out on the microcapsules produced in order to assess their thermal stability and heat storage capacity.

\section{EXPERIMENTAL}

\subsection{Materials}

n-Hexadecane (99\%, Acros Organics) was used as a model phase change material to be encapsulated for a phase change at around $20^{\circ} \mathrm{C}$ to be used in a living environment. The rice husk char was used as a Pickering emulsion stabiliser and also as the wall construction material of the n-hexadecane microcapsule. The char was made from the slow pyrolysis of Brunei rice husk at $450^{\circ} \mathrm{C}$ for 30 minutes in the presence of nitrogen gas [37], which generated $42 \mathrm{wt} \%$ of char based on dry rice husk.

Poly (diallyldimethylammonium chloride) (PDADMAC $20 \mathrm{wt} \%$ aq., 400k-500k g mol ${ }^{-1}$, Sigma Aldrich) and poly (sodium styrene sulfonate) (PSS $30 \mathrm{wt} \%$ aq., 200k g mol ${ }^{-1}$, Sigma Aldrich) were used as negatively and positively charged polymers, respectively, for layer-by-layer adsorption to fix the rice husk char particles on the emulsion droplets. Sunflower oil (Tesco UK) was used as an osmosis additive to the oil phase for better size and stability control in emulsification. Deionised water was used in all the sample preparation. 
The rice husk char received from the pyrolysis was ground dry in air using a planetary ball mill (Fritsch Pulverisette 6). The milling used a $250 \mathrm{ml}$ zirconia grinding bowl and zirconia milling balls ( $1 \mathrm{~mm}$ in diameter) of $200 \mathrm{~g}$, and was carried out at $6000 \mathrm{rpm}$ for 5 minutes to size down the rice husk char down to a nanometer range. The rice husk char (RHC) nanoparticles were analysed using laser scattering for its particle size and size distribution, and dynamic laser scattering for its surface charge measured as zeta potential. The RHC nanoparticle sample prepared dry in air was dispersed in deionised water to give aqueous suspensions with a concentration in the range of 0.5 - $2.0 \mathrm{wt} \%$. The suspensions were used as the continuous phase in the emulsification of $\mathrm{n}-$ hexadecane.

\subsection{Emulsification and encapsulation}

For a typical emulsification operation, $1 \mathrm{ml}$ of n-hexadecane and $3 \mathrm{ml}$ of RHC suspension was homogenised at 10-20k rpm using a rotor-stator homogeniser (Kinematica Polytron PT2500E) for a specified time (2-5 minutes) at room temperatures. The emulsion droplets were sampled on a glass slide and examined using an optical microscope for droplet size and size distribution, and preliminarily for the RHC nanoparticles adsorption on the oil droplet.

For encapsulation, $1 \mathrm{ml}$ of droplet sample was carefully added into $10 \mathrm{ml}$ of aqueous solution of PDADMAC with a concentration of $2.0 \mathrm{wt} \%$ or $5.0 \mathrm{wt} \%$. The mixture was gently shaken/stirred for 24 hours to allow the adsorption completion. The PDADMAC adsorbed droplet was then subjected to the adsorption of PSS (10.0 $\mathrm{mL} 5.0 \mathrm{wt} \%$ PSS) following the same operation procedure.

Samples were taken at the end of each coating operation and examined using an optical microscope. The product was then dried naturally in air at a room temperature for 2 weeks, where the relative humidity was $\sim 35-38 \%$. The dried sample was analysed using a thermogravimetric analyser and differential scanning calorimetry.

\subsection{Characterisation}

Attenuated Total Reflection (ATR) is used to measure the infrared spectroscopy of the RHC sample (Bruker Optics' ALPHA). The measurement was carried out in the wavelength range from 400 to $4000 \mathrm{~cm}^{-1}$ and the spectroscopy reported is the average of 64 scans to ensure the reliability of data collected. 
The sizes and surface zeta potential of the RHC particle was characterised by laser scattering (Molvern HPPS, Nanoziser). A Motic BA310 Digital Biological Microscope with an objective lens of 4x, 10x, 40x and 100x was used for the examination of RHC particle stabilised droplets. The size measurement was calibrated using the microbar provided by Motic.

Thermogravimetric Analysis (TGA) was performed using a Perkin Elmer Pyris 1. A sample of 5 $10 \mathrm{mg}$ was heated from room temperature to $600{ }^{\circ} \mathrm{C}$ at a heating rate of $10{ }^{\circ} \mathrm{C} /$ minute in the flow of nitrogen (purity $>99 \%$ ) at $30 \mathrm{ml} /$ minute. The nitrogen was generated by an in-house adsorber. The differential scanning calorimetric (DSC) diagrams were recorded using a METTLER TOLEDO DSC1 in the temperature range from -50 to $50^{\circ} \mathrm{C}$. Samples of $5-10 \mathrm{mg}$ were placed in aluminium pans. Both the heating and cooling rates were maintained at $10^{\circ} \mathrm{C} /$ minute using liquid nitrogen and nitrogen gas as the purging and protective gas. The specific melting heat of the phase change microcapsule measured was used for the calculation of encapsulation ratio of the phase change material by comparing with the specific melting heat of the pure phase change material using the following equation.

Encapsulation ratio $=\frac{\text { Specific melting heat of microcapsule sample }}{\text { Specific melting heat of the phase change material }} \times 100 \% \quad$ Equation 1

\section{RESULTS and DISCUSSION}

\subsection{Characterisation of the rice husk char and particles}

The RHC used was analysed for its proximate and elemental composition, as shown in Table 1. It contains $4.47 \mathrm{wt} \%$ water, $1.41 \mathrm{wt} \%$ volatile matter, $28.49 \mathrm{wt} \%$ ash and $65.63 \mathrm{wt} \%$ non-volatile organic matter as fix carbon, as received. The elemental analysis is reported on a dry basis. Along with the $29.82 \mathrm{wt} \%$ of ash, the char is composed of $53.58 \mathrm{wt} \%$ of carbon, $2.93 \mathrm{wt} \%$ of hydrogen, $1.57 \mathrm{wt} \%$ of nitrogen and $12.10 \mathrm{wt} \%$ of oxygen.

Table 1. Proximate and elemental analysis of the rice husk char

\begin{tabular}{lcllc}
\hline \multicolumn{2}{c}{ Proximate*, wt\% } & & \multicolumn{2}{l}{ Elemental, wt\%, dry basis } \\
\cline { 1 - 2 } \cline { 5 - 6 } Moisture & 4.47 & & Carbon & 53.58 \\
Volatile & 1.41 & & Hydrogen & 2.93 \\
Fixed carbon & 65.63 & & Nitrogen & 1.57 \\
Ash & 28.49 & & Oxygen** & 12.10 \\
& & & Ash & 29.82
\end{tabular}

*as received; **by difference. 
Thermogravimetric analysis in the presence of the nitrogen gas is shown in Fig. 1a. Water loss appears at a temperature lower than $100{ }^{\circ} \mathrm{C}$, suggesting moisture has been adsorbed. After the water desorption, the RHC remains virtually stable with little weight loss at temperatures up to $300{ }^{\circ} \mathrm{C}$. Results from the thermal analysis shows sufficiently stable for the application as an 190 additive in plasters, for example.

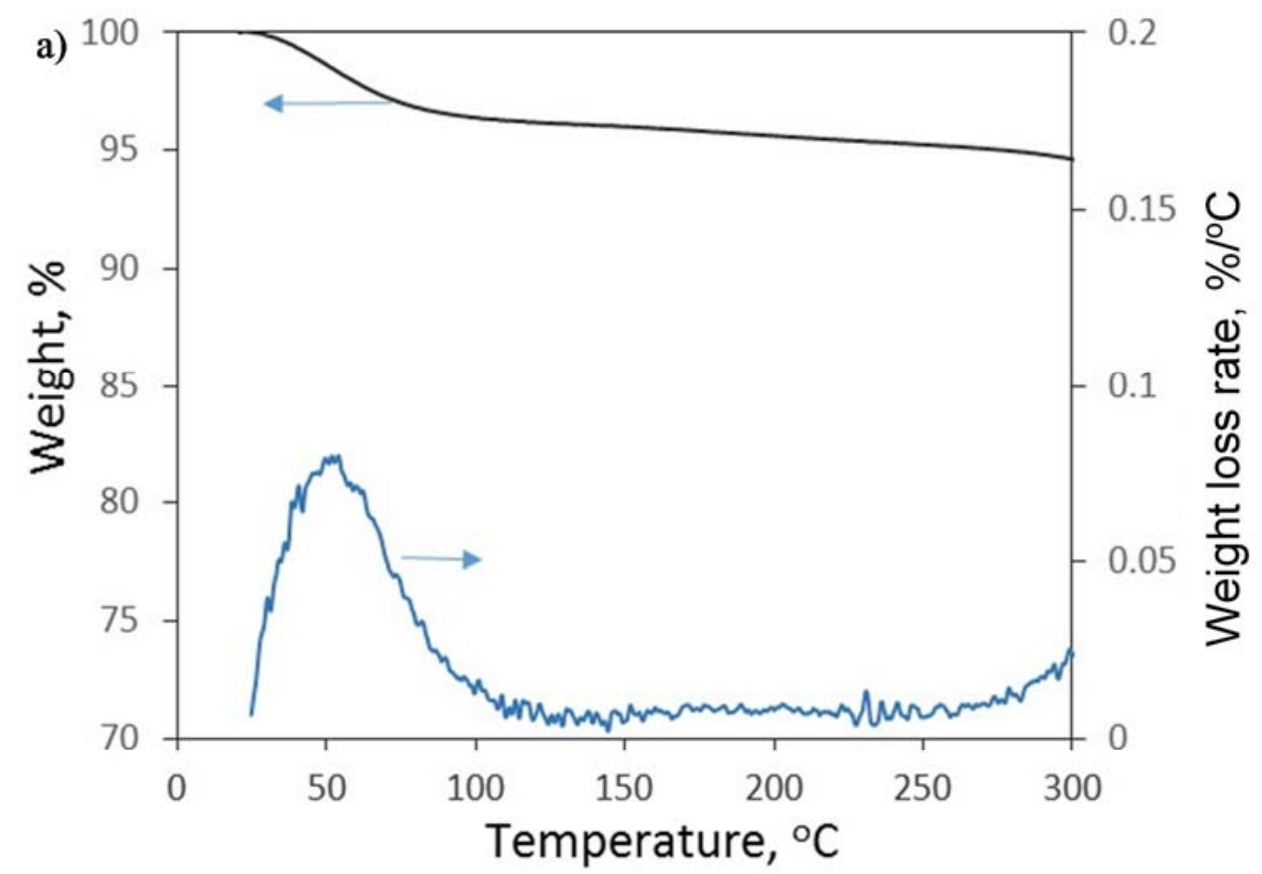

b)

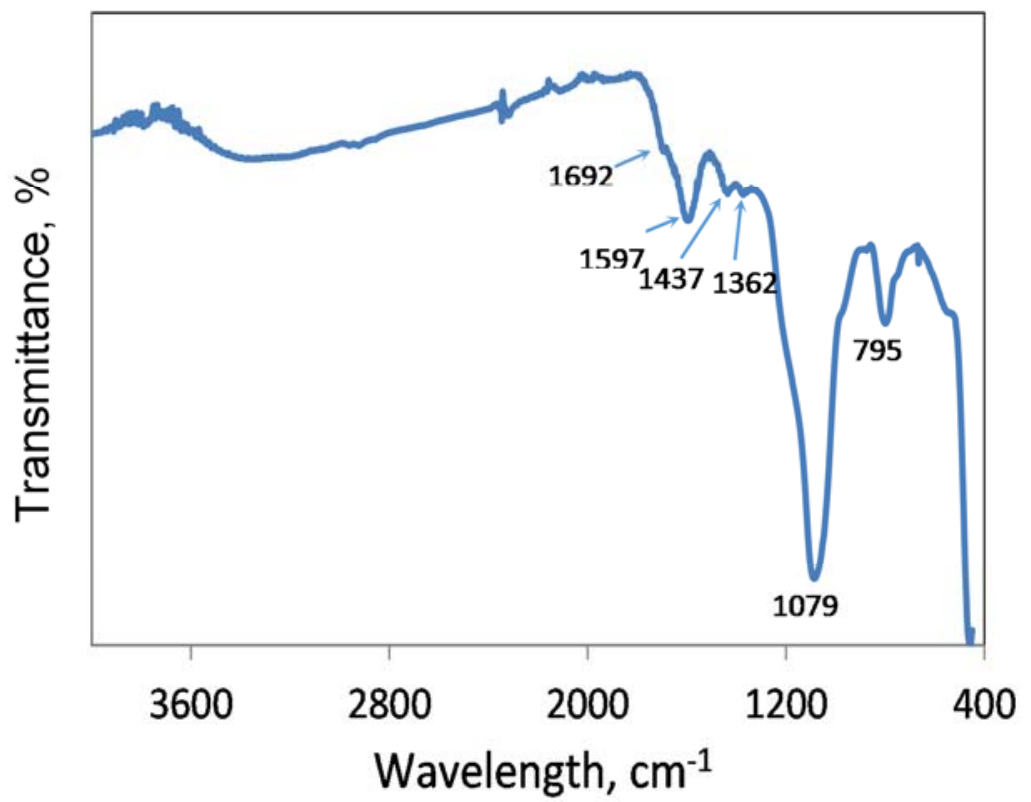

Fig. 1. (a) Thermal gravimetrical analysis of the rice husk char heated at $10 \mathrm{~K} \mathrm{~min}^{-1}$ in air; (b) ATR-FTIR spectroscopy of the rice husk char. 
The ATR-FTIR spectrum showed the combined absorption of inorganic and organic components in Fig. 1b. The strong absorption bands at $795 \mathrm{~cm}^{-1}$ and $1079 \mathrm{~cm}^{-1}$ could be assigned to (Si-O) bending and stretching vibrations respectively [38-40]. This proves the existence of silica in the RHC sample. The bands in the range $\sim 1400-1700 \mathrm{~cm}^{-1}$ are assignable to $v(\mathrm{C}=\mathrm{C})$ absorptions. Skeletal $\mathrm{C}=\mathrm{C}$ vibrations in aromatic rings could generate absorption bands at 1597 and $1437 \mathrm{~cm}^{-1}$ [41]. The bands at 1362 and $1692 \mathrm{~cm}^{-1}$ can be allocated to $\delta(\mathrm{O}-\mathrm{H})$ and $v(\mathrm{C}=\mathrm{O})$ vibrations. The existence of these aromatic carbon and oxygen-containing functional groups together with silica may generate a well-balanced hydrophilic and hydrophobic surface, which can be wetted to both oil and water. This demonstrates its suitability as a solid emulsifier.

The RHC sample was received with sizes in the range of 300-500 $\mu \mathrm{m}$. The sample was subjected to ball milling using $\mathrm{ZrO}_{2}$ milling balls of $1 \mathrm{~mm}$. After grinding at $6000 \mathrm{rpm}$ for 5 minutes, a wellpulverised sample was obtained. The sample was dispersed in deionised water and analysed by laser scattering for the size distribution and surface zeta potential. The size distribution, Fig. 2, shows a size distribution centred at $576 \mathrm{~nm}$ (zeta average size). The zeta potential measurement presented negative surface charge at $-45 \mathrm{mV}$.

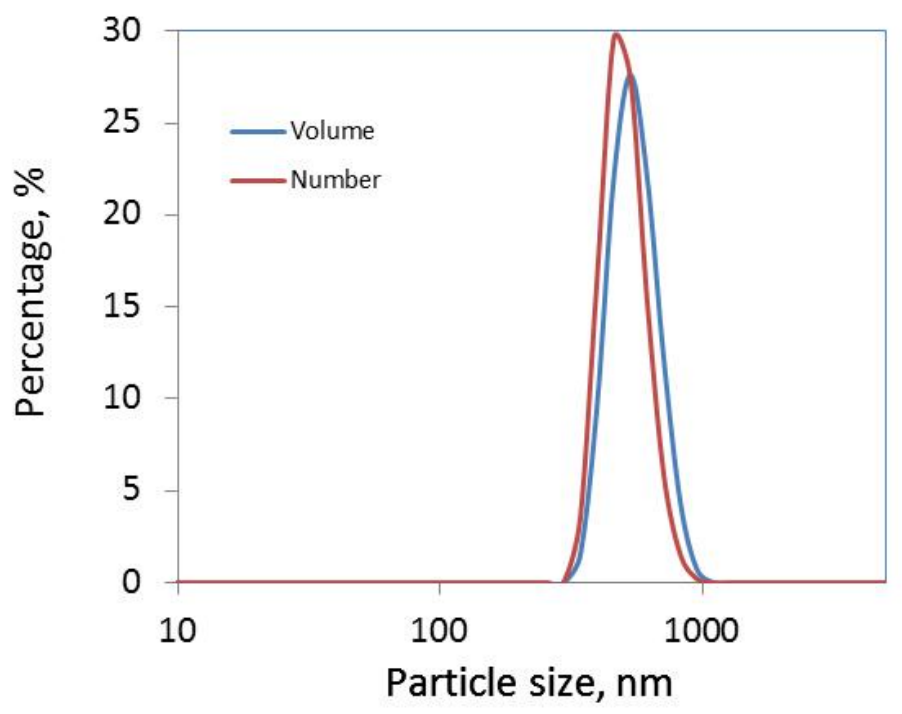

Fig. 2. Size distribution of the RHC particles measured by laser scattering.

\subsection{Emulsification}

The emulsification step aimed to break the phase change material into droplets with desired sizes, and to facilitate the adsorption of the RHC particles on the droplet surface to form a closely packed shell. These two objectives can be achieved by controlling the rotational speed of the rotor-stator homogenisation tool, volume ratio of the dispersed and continuous phases and the RHC particle 
size and concentration. In order to test the feasibility of the RHC particles as emulsifier, $3.0 \mathrm{ml}$ of its aqueous suspension at $1.0 \mathrm{wt} \%$ were emulsified with $1.0 \mathrm{ml}$ hexadecane at 15,000 $\mathrm{rpm}$ for 2 minutes. The emulsion droplets formed are displayed in Fig. 3a. The black spherical and round shapes are individual hexadecane droplets in the size range 50-100 $\mu \mathrm{m}$. The droplets are well covered by RHC particles. These droplets creamed to the top of the emulsion and showed good stability while standing. This experimental phenomenon show RHC particles have the desired wettability to both oil and water for the stabilisation of the emulsion droplets.
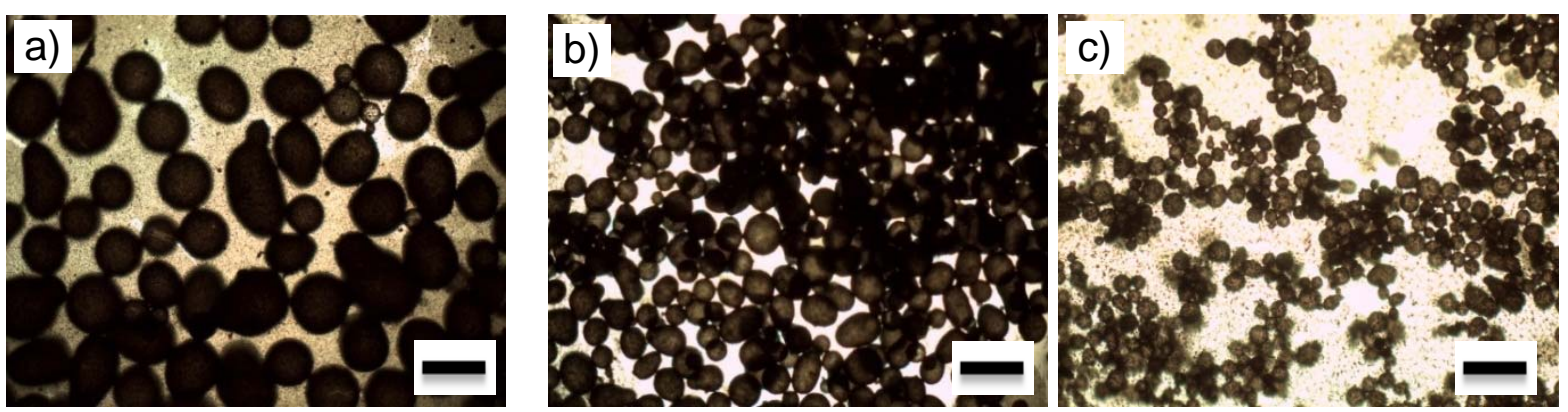

Fig. 3. Optical micrographs of hexadecane droplets in water stabilised by the rice husk char particles: a) $1.0 \mathrm{ml}$ hexadecane in $3.0 \mathrm{ml}$ of $1.0 \mathrm{wt} \% \mathrm{RHC}$, (b) $1.0 \mathrm{ml}$ hexadecane in $3.0 \mathrm{ml}$ of 2.0 wt\% RHC and c) $0.5 \mathrm{ml}$ hexadecane in $3 \mathrm{ml}$ of $2.0 \mathrm{wt} \%$ RHC suspension. Homogenised at $15 \mathrm{k}$ rpm for 2 minutes. The scale bar denotes $100 \mu \mathrm{m}$.

Comparatively, another emulsion was prepared under the same condition with the RHC particle concentration in water being increased to $2.0 \mathrm{wt} \%$ (as shown in Figure $3 \mathrm{~b}$ ). The diameter of the black-coloured droplets decreases to $\sim 30 \mu \mathrm{m}$. From this it is obvious that higher particle concentration produced smaller droplets due to faster adsorption onto the droplet surface. The images in Fig. 3 show the existence of surplus free particles.

With a char concentration of $2.0 \mathrm{wt} \%$, the oil to aqueous phase ratio was decreased to $0.5 \mathrm{ml} / 3 \mathrm{ml}$ in order to examine the effect of phase volume ratio on the droplet formation. The droplet appearances can be seen in Fig. 3c. At a low volume ratio of $0.5 \mathrm{ml} / 3.0 \mathrm{ml}$, the oil droplets become significantly smaller to approximately $10 \mu \mathrm{m}$. Observations showed good coverage of RHC particles on the droplets and appear more translucent due to the smaller size, demonstrating the monolayer adsorption mechanism for RHC particles.

Hexadecane has a melting point at $18.7^{\circ} \mathrm{C}$, viscosity close to $3 \mathrm{mPas}$ and solubility in water at $6.0 \times 10^{-3} \mathrm{~g} / 100 \mathrm{~g}$ water at $20^{\circ} \mathrm{C}$. Its droplets in a complex emulsion environment will encounter stability challenges similar to that seen in miniemulsion polymerisation [42]. In the mini-emulsion polymerisation, monomers in droplets tend to escape into the continuous phase during 
polymerisation. A hydrophobic agent is added in the monomer phase to increasing the osmosis pressure inside the droplet. This characteristic can effectively avoid monomers escaping into the continuous phase. This strategy can be used here. Sunflower oil as a hydrophobic agent was added into hexadecane at $1.0 \mathrm{wt} \%$. Such oil phase of $0.5 \mathrm{ml}$ was homogenised in $3.0 \mathrm{ml}$ of the RHC particle suspension of $2.0 \mathrm{wt} \%$ at $10 \mathrm{k}$ rpm for 5 minutes. The emulsion prepared is shown in Figure 4. A slower homogenisation speed of $10 \mathrm{k} \mathrm{rpm}$ and a longer time of 5 minutes were used to obtain more uniform droplets with a better surface coverage. The emulsion droplets prepared look robust, covered well by the RHC particles in the desired size range of $10-30 \mu \mathrm{m}$, as shown in the inset, for interior wall applications $[5,6]$. The emulsion droplets were then subjected to encapsulation.

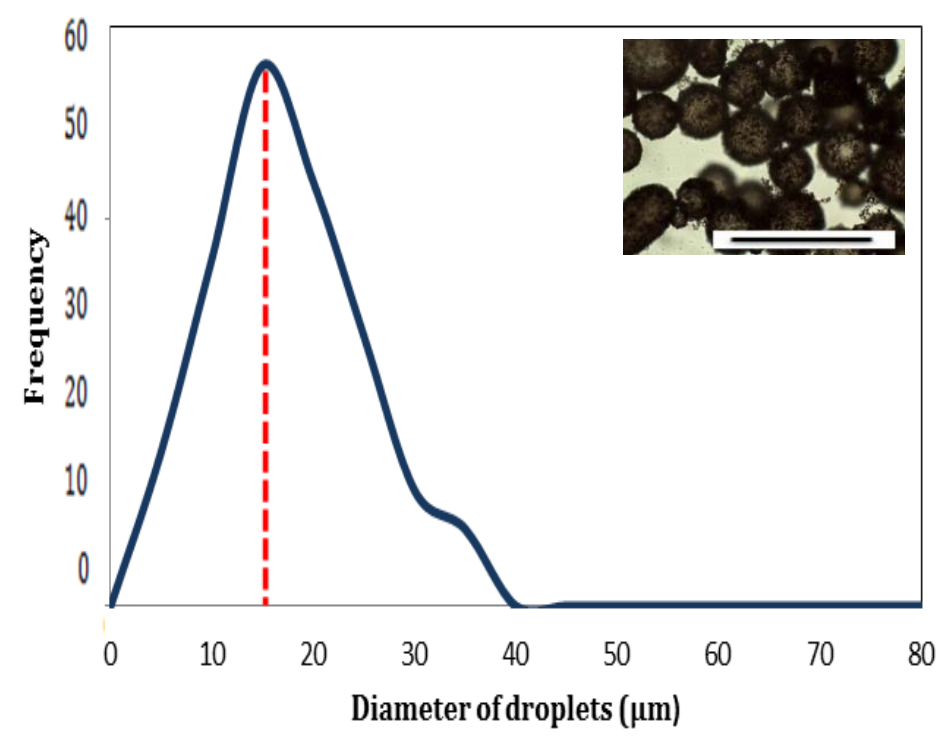

Fig. 4. Size distribution of the hexadecane droplets. Prepared from $0.5 \mathrm{ml}$ hexadecane (including $1.0 \mathrm{wt} \%$ of sunflower oil) and $3.0 \mathrm{ml}$ of $2.0 \mathrm{wt} \%$ aqueous RHC particle suspension at the rotational speed of 10k rpm for 5 minutes. Inset shows the droplets with the scale bar denoting $100 \mu \mathrm{m}$.

\subsection{Encapsulation by layer-by-layer assembly}

The encapsulation was carried out by alternative adsorption of positively charged polymer PDADMAC and negatively charged PSS. The RHC is negatively charged on the surface and has a zeta potential of $-45 \mathrm{mV}$. Due to this negative charge, the positively charged polymer PDADMAC was used for the first layer of adsorptive coating. The effect of PDADMAC concentration on the coating was examined using aqueous solutions at 2.0 and $5.0 \mathrm{wt} \%$. On mixing the emulsion mixture with PDADMAC solution, the free RHC particles flocculated. This led to particle sedimentation with time. The microcapsules produced after being gently stirred for 24 
hours were sampled from the top layer of the mixture for microscopic examination. Images are shown in Fig. 5 a and $b$.
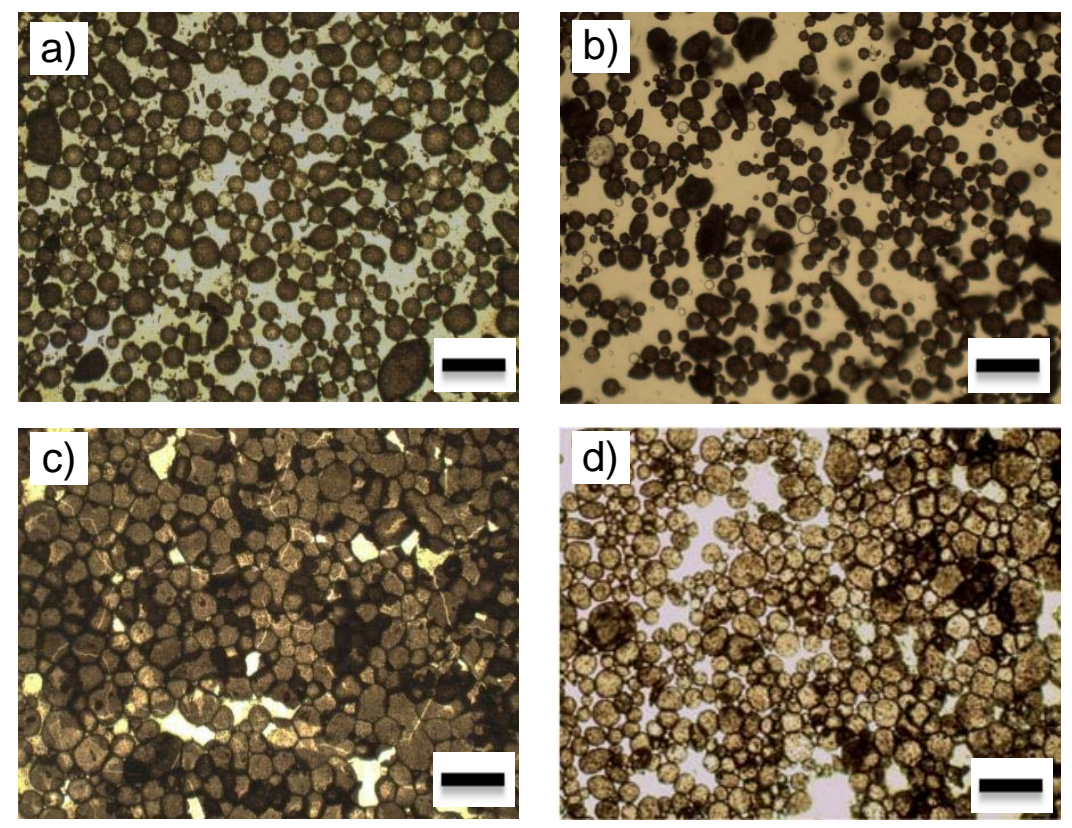

Fig. 5. Optical micrographs of the microcapsules coated by $2.0 \mathrm{wt} \%$ PDADMAC (a. wet; c dried) and $5.0 \mathrm{wt} \%$ PDADMAC (b. wet; d. dried). The scale bar denotes $100 \mu \mathrm{m}$.

Both samples show microcapsules in the similar size range to their precursor emulsion. Close observation confirms that the microcapsules coated by $5.0 \mathrm{wt} \%$ PDADMAC are structurally more intact compared to that coated by $2.0 \mathrm{wt} \%$ PDADMAC. The microcapsules were also closely examined after the water vaporisation. The microcapsules coated with $2.0 \mathrm{wt} \%$ PDADMAC showed clear cracks and deformation due to aggregation, Fig. 5c. In contrast, the microcapsules coated with $5.0 \mathrm{wt} \%$ PDADMAC did not rupture upon drying and remained as whole microcapsules, Fig. 5d. The $5.0 \mathrm{wt} \%$ PDADMAC coated sample, therefore, was coated further by the negatively charged PSS, and then coated by PDADMAC again, forming two and three layercoated microcapsules as shown in Fig. 6 a and c, respectively.

The two- and three-layer coated microcapsules remained similar in size range to their precusor emulsion. The capsules had undamaged shells when suspended in water (Fig. 6 a and c), and after drying (Fig. $6 \mathrm{~b}$ and d). It was observed that most of the three-layer coated microcapsules settled at the bottom of the vial. This indicated that the three-layer coated microcapsules became heavier than water, which may be due to leaching of hexadecane. On the other hand, the microcapsule shell remained undamaged, indicating the shell is relatively stable. 

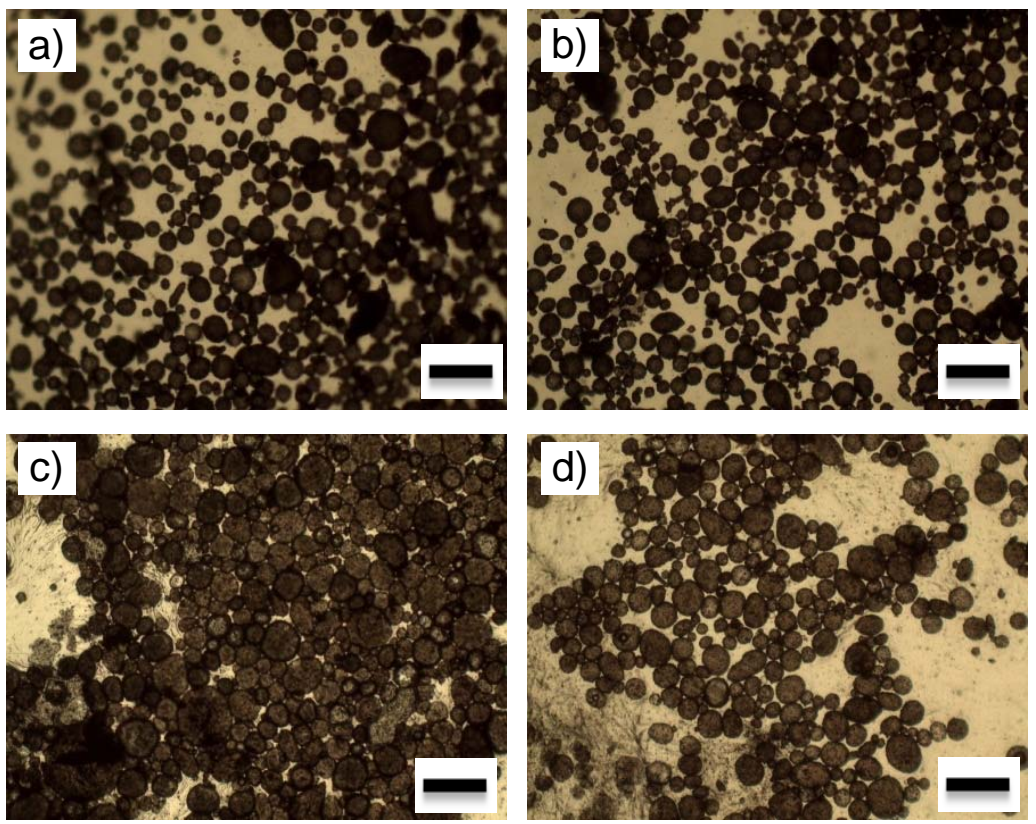

Fig. 6. Optical micrographs of the PDADMAC/PSS-coated microcapsules: a) wet; c) dried and PDADMAC/PSS/PDADMAC coated microcapsules: b) wet; d) dried. The scale bar denotes 100 $\mu \mathrm{m}$.

\subsection{Thermal analysis of the microcapsules}

296 The thermal stability of the microcapsules was assessed using the TGA and DSC. Results from TGA are shown in Fig. 7.

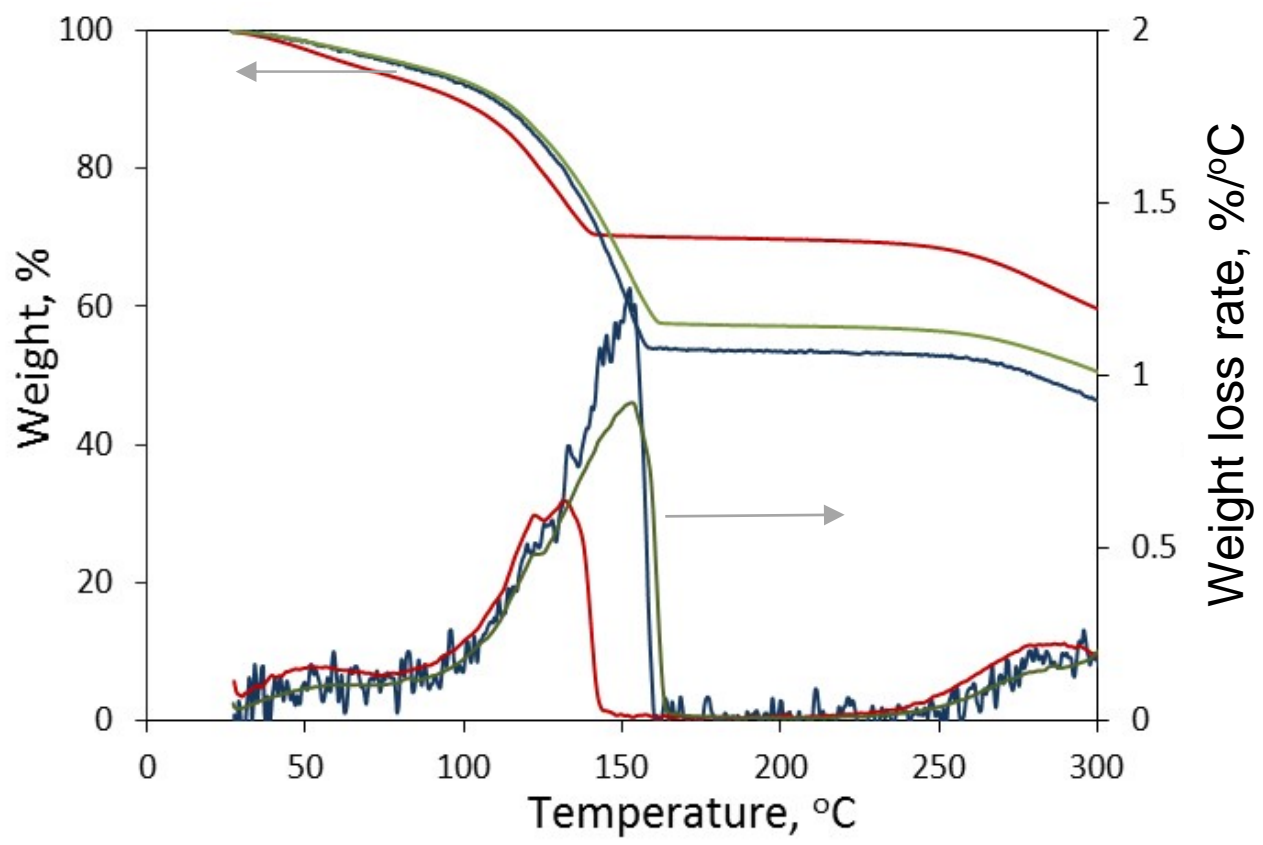

Fig. 7. Thermogravimetric analysis of microcapsules: (blue) PDADMAC-coated, (green) PDADMAC/PSS-coated, (red) PDADMAC/PSS/PDADMAC-coated. 
The test was carried out in the presence of flowing $\mathrm{N}_{2}$ gas. The weight loss profile shows a moisture loss $\sim 5 \mathrm{wt} \%$ before $75^{\circ} \mathrm{C}$ when microcapsules were naturally dried. This temperature is distinguished by the inflection point of the weight loss rate. The weight loss between 75 and $165^{\circ} \mathrm{C}$ can be assigned to hexadecane. This temperature range is significantly lower than the boiling point of hexadecane at $286.5^{\circ} \mathrm{C}$, probably due to the existence of trace oxygen in the carrier gas $\left(\mathrm{N}_{2}\right)$ and the flash temperature of hexadecane $\left(93^{\circ} \mathrm{C}\right)$. The sample weight remained virtually constant between $165-250^{\circ} \mathrm{C}$, showing stability of the RHC particle and coating polymers in this temperature range. Both the RHC and coating polymers started to decompose at temperature over $250^{\circ} \mathrm{C}$ as proved in Fig. 1 as well as studies into polymer degradation and stability [43]. The weight loss of the three samples are summarised in Table 2.

Table 2. Thermal analysis results of RHC microcapsules

\begin{tabular}{|c|c|c|c|c|c|}
\hline \multirow{2}{*}{ SAMPLE } & \multicolumn{3}{|c|}{ Weight loss, wt $\%$ by TGA } & \multirow{2}{*}{$\begin{array}{l}\text { Melting Heat } \\
\qquad\left(\mathrm{kJ} \mathrm{kg}^{-1}\right)\end{array}$} & \multirow{2}{*}{$\begin{array}{l}\text { PCM, } \\
\text { wt } \% \text { by DSC }\end{array}$} \\
\hline & $75^{\circ} \mathrm{C}$ & $75-165^{\circ} \mathrm{C}$ & $165-400^{\circ} \mathrm{C}$ & & \\
\hline One layer & 4.25 & 41.77 & 21.22 & -93.22 & 41.03 \\
\hline Two layers & 4.04 & 38.16 & 19.17 & -80.88 & 35.60 \\
\hline Three layers & 6.33 & 23.54 & 22.56 & -60.63 & 26.69 \\
\hline
\end{tabular}

Weight loss in the temperature range of $75^{\circ} \mathrm{C}$ to $165^{\circ} \mathrm{C}$ showed decreased hexadecane encapsulation ratio from 41.77 to $23.54 \mathrm{wt} \%$ as the number of polymer coating layers increased. Theoretical calculation illustrates that the hexadecane encapsulation ratio is controlled by the size ratio of the nanoparticles and microcapsules. The smaller the size ratio, the higher the encapsulation ratio can be. The highest hexadecane encapsulation ratio measured was $41.77 \mathrm{wt} \%$, this reflects the size ratio of the nanoparticles and microcapsules. However this is lower than theoretically calculated values. The leaching of hexadecane is accountable for the lower encapsulation ratio. As discussed earlier, higher encapsulation ratios i.e. $65 \mathrm{wt} \%$ can be achieved when smaller size ratio is used [28].

The microcapsule samples were analysed by DSC (Fig. 8). The heat intake and release profiles show the melting temperatures of the three samples are close to that of hexadecane at $\sim 20{ }^{\circ} \mathrm{C}$, while the solidification temperatures shift to $13.5^{\circ} \mathrm{C}$, which is significantly lower than the $18^{\circ} \mathrm{C}$ melting point. The melting and crystallisation enthalpies of RHC microcapsules decreased as the number of polymer layers increased. One-layer coated RHC microcapsules released a latent heat of $93.22 \mathrm{~kJ} / \mathrm{kg}$, equivalent to the inclusion of hexadecane at $41.0 \mathrm{wt} \%$. The two-layer coated released $80.88 \mathrm{~kJ} / \mathrm{kg}(120 \mathrm{~kJ} / \mathrm{L})$, corresponding to $35.60 \mathrm{wt} \%$ of hexadecane, and the three layer 


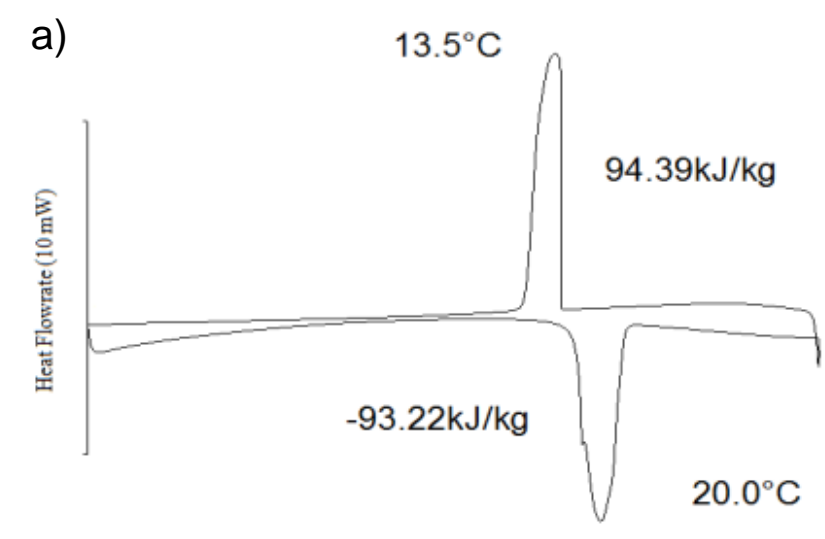

329
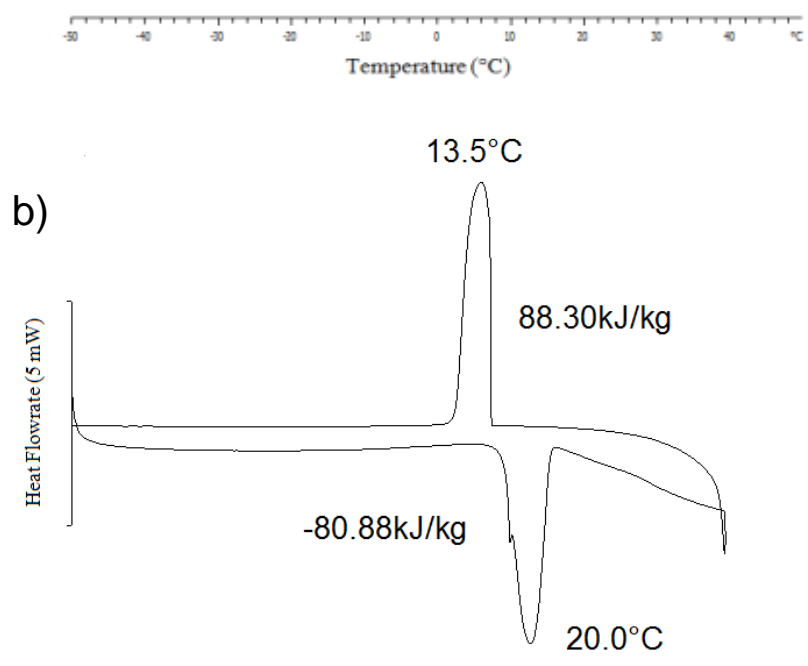

330
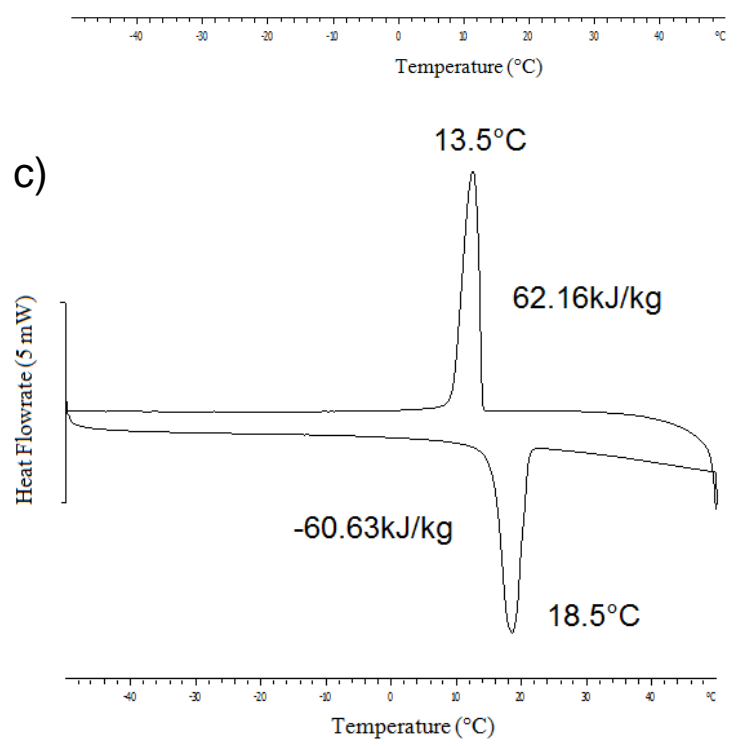

Fig. 8. DSC thermographs of microcapsules coated with a) one layer, b) two layers and c) three layers of polymers. Heat rate $10 \mathrm{~K} \mathrm{~min}^{-1}$.

334 coated released $60.63 \mathrm{~kJ} / \mathrm{kg}$ of heat corresponding to an inclusion of $26.69 \mathrm{wt} \%$ hexadecane. The 335 encapsulation ratios matched well with the weight loss measured TGA. The significant decrease in the inclusion of hexadecane could be caused by the osmosis pressure of the continuous phase that is generated by the high polymer concentration. The osmosis pressure withdraws the 
hexadecane into the continuous aqueous phase outside. This osmosis-driven leach could be overcome by controlling the relative population of the polymer chains in the continuous phase and/or by adding more osmosis agent in the disperse phase. Such kind of control has been successfully achieved in mini emulsion polymerisation, and also applied in our on-going work with significant higher encapsulation results.

The phase change microcapsules prepared in this study were designed in the size range of 10-30 $\mu \mathrm{m}$ for civil engineering applications in stagnant conditions. Our ongoing research is to develop phase change microcapsule slurries as working fluids for thermal energy recovery and storage. In slurries, the microcapsule shell forms thermal conductive network structures to enhance heat transfer and the phase change core plays an important role in increasing the heat density. To fulfil the heat storage capacity of the phase change material encapsulated, the heat transfer across the shell to the centre of the core (phase change material inside) needs to be achieved within the contact time while recovering or releasing heat. The heat transfer rate is determined by the overall heat transfer resistance, which is the sum of those from the shell and core of microcapsules. When the shell is more thermally conductive, the heat transfer resistance from the core will play a determining role. In order to formulate phase change microcapsule slurries with both high heat transfer rate and high heat density, factors such as thermal conductivities of the shell and core, size and shape of microcapsules need to be carefully designed. Simulation work has been carried out to assist our design of bespoke phase change microcapsules slurries.

\section{CONCLUSIONS}

This research combines carbon capture from biomass processing and utilisation for energy storage through carbon-based phase change microcapsules. The development of carbon-based phase change microcapsules aims to achieve higher thermal conductivity. The carbon material used, ricehusk-char, was a by-product in bio-oil production of rice husk. A phase change material, hexadecane, has been successfully encapsulated with desired sizes by using the rice husk char particles via emulsification. The rice husk char particles were fixed on the surface of the microcapsules by polymer chains adsorbed through layer-by-layer assembly. The microcapsules produced were analysed through DSC and TGA, it was revealed that one- and two-layer polymer coated microcapsules accommodated $\sim 41.0$ and $35.6 \mathrm{wt} \%$ of hexadecane respectively, corresponding to phase change enthalpies of 93.2 and $80.9 \mathrm{~kJ} / \mathrm{kg}\left(120 \mathrm{MJ} / \mathrm{m}^{3}\right)$. 
372 Dr Yuan Q would like thanking the School of Engineering and Sciences for an initiative funding, 373 and European Bioenergy Research Institute for the funding of purchasing a dyno mill. The authors 374 would like thanking Drs Titiloye J O and Bakar M S A for providing the rice husk char, Professor 375 Chen G. and Dr Hu D for assisting the dry grinding and EPSRC Equipment Pool for the loan of 376 Malvern HPPS. 


\section{REFERENCES}

[1] UK renewable energy roadmap: 2013 update. In: Change DoEC, editor. London2013.

[2] Zhang P, Ma ZW, Wang RZ. An overview of phase change material slurries: MPCS and CHS. Renew Sust Energ Rev. 2010;14:598-614.

[3] Sharma A, Tyagi VV, Chen CR, Buddhi D. Review on thermal energy storage with phase change materials and applications. Renew Sust Energ Rev. 2009;13:318-45.

[4] Jamekhorshid A, Sadrameli SM, Farid M. A review of microencapsulation methods of phase change materials (PCMs) as a thermal energy storage (TES) medium. Renew Sust Energ Rev. 2014;31:531-42.

[5] Schmidt M. Phase Change Materials - latent heat storage for interior climate control. In: BASF, editor. Ludwigshafen, Germany2007.

[6] Cool Buildings with Micronal®PCM. In: BASF, editor. Germany 2014.

[7] Kapsalis V, Karamanis D. Solar thermal energy storage and heat pumps with phase change materials. Applied Thermal Engineering. 2016;99:1212-24.

[8] Huang MJ, Eames PC, McCormack S, Griffiths P, Hewitt NJ. Microencapsulated phase change slurries for thermal energy storage in a residential solar energy system. Renew Energ. 2011;36:2932-9.

[9] Gschwander S, Schossig P, Henning H. Micro-encapsulated paraffin in phase-change slurries. Solar Energy Materials and Solar Cells. 2005;89:307-15.

[10] Su JF, Ren L, Wang LX. Preparation and mechanical properties of thermal energy storage microcapsules. Colloid Polym Sci. 2005;284:224-8.

[11] Shin Y, Yoo DI, Son K. Development of thermoregulating textile materials with microencapsulated phase change materials (PCM). II. Preparation and application of PCM microcapsules. J Appl Polym Sci. 2005;96:2005-10.

[12] Malekipirbazari M, Sadrameli SM, Dorkoosh F, Sharifi H. Synthetic and physical characterization of phase change materials microencapsulated by complex coacervation for thermal energy storage applications. Int J Energ Res. 2014;38:1492-500.

[13] Fang YT, Liu X, Liang XH, Liu H, Gao XN, Zhang ZG. Ultrasonic synthesis and characterization of polystyrene/n-dotriacontane composite nanoencapsulated phase change material for thermal energy storage. Appl Energ. 2014;132:551-6.

[14] Karkri M, Lachheb M, Nogellova Z, Boh B, Sumiga B, AlMaadeed MA, et al. Thermal properties of phase-change materials based on high-density polyethylene filled with microencapsulated paraffin wax for thermal energy storage. Energy and Buildings. 2015;88:144-52.

[15] Zhang X, Wang X, Wu D. Design and synthesis of multifunctional microencapsulated phase change materials with silver/silica double-layered shell for thermal energy storage, electrical conduction and antimicrobial effectiveness. Energy. 2016;111:498-512.

[16] Al-Shannaq R, Kurdi J, Al-Muhtaseb S, Farid M. Innovative method of metal coating of microcapsules containing phase change materials. Sol Energy. 2016;129:54-64.

[17] Jiang FY, Wang XD, Wu DZ. Design and synthesis of magnetic microcapsules based on neicosane core and $\mathrm{Fe} 3 \mathrm{O} 4 / \mathrm{SiO} 2$ hybrid shell for dual-functional phase change materials. Appl Energ. 2014; 134:456-68.

[18] Yang YY, Kuang J, Wang H, Song GL, Liu Y, Tang GY. Enhancement in thermal property of phase change microcapsules with modified silicon nitride for solar energy. Solar Energy Materials and Solar Cells. 2016;151:89-95.

[19] Wang TY, Wang SF, Luo RL, Zhu CY, Akiyama T, Zhang ZG. Microencapsulation of phase change materials with binary cores and calcium carbonate shell for thermal energy storage. Appl Energ. 2016;171:113-9.

[20] Wang T, Wang S, Geng L, Fang Y. Enhancement on thermal properties of paraffin/calcium carbonate phase change microcapsules with carbon network. Appl Energ. 2016;179:601-8. 
[21] Group S. How can energy be produced efficiently? How can it best be stored? How can we use it in a resource-friendly way? Questions about energy are questions about the future. Germany2016.

[22] Koschenz M, Lehmann B. Development of a thermally activated ceiling panel with PCM for application in lightweight and retrofitted buildings. Energ Buildings. 2004;36:567-78.

[23] Li M, Chen MR, Wu ZS. Enhancement in thermal property and mechanical property of phase change microcapsule with modified carbon nanotube. Appl Energ. 2014;127:166-71.

[24] Yavari F, Fard HR, Pashayi K, Rafiee MA, Zamiri A, Yu ZZ, et al. Enhanced Thermal Conductivity in a Nanostructured Phase Change Composite due to Low Concentration Graphene Additives. J Phys Chem C. 2011;115:8753-8.

[25] Fan LW, Fang X, Wang X, Zeng Y, Xiao YQ, Yu ZT, et al. Effects of various carbon nanofillers on the thermal conductivity and energy storage properties of paraffin-based nanocomposite phase change materials. Appl Energ. 2013;110:163-72.

[26] Binks BP, Whitby CP. Silica particle-stabilized emulsions of silicone oil and water: aspects of emulsification. Langmuir. 2004;20:1130-7.Jin Y, Lee W, Musina Z, Ding Y. A one-step method for producing microencapsulated phase change materials. Particuology. 2010;8:588-90.

[27] Yuan Q, Cayre OJ, Manga M, Williams RA, Biggs S. Preparation of particle-stabilized emulsions using membrane emulsification. Soft Matter. 2010;6:1580.

[28] Jin Y, Lee W, Musina Z, Ding Y. A one-step method for producing microencapsulated phase change materials. Particuology. 2010;8:588-90.

[29] Xiao B, Yuan Q, Williams RA. Exceptional function of nanoporous metal organic framework particles in emulsion stabilisation. Chem Commun (Camb). 2013;49:8208-10.

[30] Pang M, Cairns AJ, Liu Y, Belmabkhout Y, Zeng HC, Eddaoudi M. Synthesis and integration of Fe-soc-MOF cubes into colloidosomes via a single-step emulsion-based approach. J Am Chem Soc. 2013;135:10234-7.

[31] Shen M, Resasco DE. Emulsions stabilized by carbon nanotube-silica nanohybrids. Langmuir. 2009;25:10843-51.

[32] Yuan QC, Williams RA. CO-stabilisation mechanisms of nanoparticles and surfactants in Pickering Emulsions produced by membrane emulsification. Journal of Membrane Science. 2016;497:221-8.

[33] Yuan Q, Cayre OJ, Fujii S, Armes SP, Williams RA, Biggs S. Responsive core-shell latex particles as colloidosome microcapsule membranes. Langmuir. 2010;26:18408-14.

[34] Dinsmore AD, Hsu MF, Nikolaides MG, Marquez M, Bausch AR, Weitz DA. Colloidosomes: selectively permeable capsules composed of colloidal particles. Science. 2002;298:1006-9.

[35] Tsai WT, Lee MK, Chang YM. Fast pyrolysis of rice husk: Product yields and compositions. Bioresour Technol. 2007;98:22-8.

[36] Ltd B. RICE HUSK ASH MARKET STUDY. 2003.

[37] Abu Bakar MS, Titiloye JO. Catalytic pyrolysis of rice husk for bio-oil production. J Anal Appl Pyrol. 2013;103:362-8.

[38] Innocenzi P. Infrared spectroscopy of sol-gel derived silica-based films: a spectramicrostructure overview. J Non-Cryst Solids. 2003;316:309-19.

[39] Moore C, Perova TS, Kennedy B, Berwick K, Shaganov II, Moore RA. Study of structure and quality of different silicon oxides using FTIR and Raman microscopy. P Soc Photo-Opt Ins. 2003;4876:1247-56.

[40] Abadri MHS, Delbari A, Fakoor Z, Baedi J. Effects of Annealing Temperature on Infrared Spectra of SiO2 Extracted From Rice Husk. J Ceram Sci Technol. 2015;6:41-5.

[41] GomezSerrano V, PastorVillegas J, PerezFlorindo A, DuranValle C. FT-IR study of rockrose and of char and activated carbon. J Anal Appl Pyrol. 1996;36:71-80.

[42] Landfester K, Bechthold N, Tiarks F, Antonietti M. Formulation and stability mechanisms of polymerizable miniemulsions. Macromolecules. 1999;32:5222-8. 
[43] van Krevelen DW, te Nijenhuis K, Properties of Polymers. Elsevier BU 2009. 